\title{
REDES DIGITALES Y EVENTO TRADICIONAL: CASO FESTAPÈDIA
}

\author{
María Estela Bernad-Monferrer1: Universitat Jaume I de Castellón. España \\ bernad@com.uji.es
}

Magdalena Mut-Camacho: Universitat Jaume I de Castellón. España magda.mut@com.uji.es

\section{RESUMEN}

Internet y las nuevas tecnologías de la comunicación son una plataforma excelente para difundir los eventos tradicionales, convirtiéndose en un instrumento fundamental en un mundo globalizado, donde las ciudades son en realidad productos cuya identidad y valores han de ser diseñados y comercializados. Los eventos tradicionales, son parte del patrimonio del territorio que unido al cambio producido en el estilo de vida de las sociedades occidentales, lo convierten en un fuerte atractivo para el nuevo concepto de turista, más responsable, mejor informado, que demanda lo particular, lo sorpresivo, lo experiencial y distinto que ofrece cada lugar. Nos encontramos ante patrimonio cultural inmaterial, elementos intangibles pero que diferencian, personalizan y dan identidad a los territorios. El evento tradicional, es en muchas ocasiones la carta de presentación y valor reputacional de las poblaciones, debiendo darlo a conocer a los futuros visitantes interesados en la peculiaridad, cultura e historia del territorio. Así, la web se presenta como una herramienta para acceder al público global que pueda sentirse atraído por este tipo de eventos y sirve a la vez para proyectar el lugar donde se realizan. En este caso, el portal web Festapedia surge para recoger todos los contenidos relativos a las Fiestas de la ciudad de Castellón, impulsando y poniendo en valor dicha población. Así, desde la perspectiva local, se presenta un modelo de documentación de la memoria que tiene una aplicación universal, y que ayudará a mejorar la proyección de la ciudad, diferenciándola de otros lugares y haciendo que consiga visibilidad y notoriedad.

\footnotetext{
${ }^{1}$ Autor correspondiente

María Estela Bernad-Monferrer: Profesora Contratada Doctora. Universitat Jaume I de Castellón. Correo: bernad@com.uji.es
} 
PALABRAS CLAVE: Redes digitales - Patrimonio Cultural - Evento Tradicional Valor reputacional - Proyección

\title{
DIGITAL NETWORKS AND TRADITIONAL EVENT: THE CASE STUDY OF FESTAPÈDIA
}

\begin{abstract}
Internet and new communication technologies are an excellent platform to disseminate the traditional events, becoming a key tool in a globalized world, where cities are considered actually like products where their identity and values have to be specifically designed and marketed. Traditional events are part of the territories heritage and together with the change in life style in ours societies, make a strong appeal for the new concept of a tourist, who is more responsible, better informed, require the particular, the surprising, and different experiences which each location offers. We are dealing with a "non-material" cultural heritage, with intangible elements given a differentiated and personalized identity to the territories. Many times, the traditional event is the introduction letter and part of the reputational value of cities, and consequently it has to become known for the prospective visitors interested in the uniqueness, culture and history of the territory. Thus, the web appears as a tool to access the global public that can be attracted to these events and at the same time serves to project the city where performed. In this case, the web Festapedia comes up to collect all the content relating to the festivities of the city of Castellón, promoting and demonstrating the value of that population. Thus, from the local perspective, a model of memory documentation with an universal application is presented. This model will help to improve the projection of the city, distinguishing it from other places and making possible that the city gets visibility and notoriety.
\end{abstract}

KEY WORDS: Digital networks - cultural heritage - traditional events - reputational value - Projection

\section{INTRODUCCIÓN}


En los últimos tiempos la comunicación ha cambiado de manera vertiginosa, modificando estructuras que parecían sólidas, abriéndose a la participación de la ciudadanía. Lo que antes era jerarquía y unidireccionalidad, ahora se muestra abierto y bidireccional. Gran parte de culpa la tiene el fenómeno Internet. Desde que en los años setenta comenzase su andadura una nueva era ha comportado un escenario distinto y cambiante en el mundo de la comunicación. Internet ha revolucionado los cimientos establecidos pudiéndose augurar que estamos ante un cambio de paradigma que es aprovechado por el mundo empresarial para buscar nuevos públicos y una plataforma idónea donde ofertar sus productos.

El sector turístico no es extraño a este fenómeno, nos movemos en un contexto en el que la competitividad del sector turístico es feroz. Los destinos turísticos rivalizan por ofertar atractivos singulares y especiales que les diferencien de la competencia. Esta lucha competitiva si se realiza de forma correcta y adecuada, puede tener resultados positivos para el propio territorio/ciudad así como también puede ser fuente de riqueza para los ciudadanos.

En este contexto las ciudades y territorios intentan diferenciarse aportando valores seductores y peculiares. De esta manera, el patrimonio cultural de un territorio se convierte en una herramienta fundamental, para atraer un público concreto que quiera disfrutarlo. El turismo cultural está de moda, y el target al que se dirige reúne unas particularidades que lo hacen interesante, por esto la recuperación, conservación y difusión, del patrimonio cultural de las ciudades se muestra imprescindible para abrir nuevos caminos ligados a la comunicación y al turismo y en este sentido, la difusión a través de la web, es algo imprescindible para salvar distancias y llegar a futuros públicos interesados.

Dentro del Patrimonio cultural de los pueblos, las fiestas populares, es decir, los eventos tradicionales, son una parte importantísima del mismo. Este patrimonio unido al cambio producido en el estilo de vida de las sociedades occidentales, lo convierten en un fuerte atractivo para el nuevo concepto de turista, más responsable, mejor informado, que demanda lo particular, lo sorpresivo, lo experiencial y distinto que ofrece cada lugar.

Este tipo de evento es en muchas ocasiones la carta de presentación y valor reputacional de las poblaciones, debiendo darlo a conocer a los futuros visitantes interesados en la peculiaridad, cultura e historia del territorio. Así, la web se presenta como una herramienta para acceder al público global que pueda sentirse atraído por este tipo de eventos y sirve a la vez para proyectar el lugar donde se realizan. Esta comunicación explica un proyecto en el que hemos sido participes, donde se construye un portal web para recoger todos los contenidos relativos a las Fiestas de la ciudad de Castellón, impulsando y poniendo en valor dicha población.

Festa Pèdia, que es el nombre del proyecto, no pretende ser simplemente un proyecto relacionado con la historia castellonense contemporánea, sino que se presenta como un proyecto pionero, de referencia para otras Fiestas tradicionales. Así, desde la 
perspectiva local, se muestra un modelo de documentación de la memoria que tiene una aplicación universal, y que ayudará a mejorar la proyección de la ciudad, diferenciándola de otros lugares y haciendo que consiga visibilidad y notoriedad.

\section{DESARROLLO}

\subsection{El Evento Tradicional como parte del patrimonio cultural intangible}

El patrimonio cultural, es el conjunto de todos los bienes, materiales e inmateriales, que por su valor propio, deben ser considerados de interés relevante para la permanencia de la identidad y la cultura de un pueblo. Como se ha indicado, el evento tradicional es patrimonio cultural, quedando circunscrito al patrimonio cultural intangible/inmaterial que aglutina, a su vez, gran cantidad de elementos culturales como artes del espectáculo, rituales, indumentaria, música, gastronomía, historia, tradiciones, danza, artesanía etc.. En este sentido, el evento tradicional se entiende como patrimonio cultural vivo, con una garantía de creatividad permanente.

Además, el evento tradicional, como patrimonio cultural, supone un revestimiento emocional para su propietario, que altera sus procesos de percepción e identificación, otorgándole un significado particular que no lo tiene para una persona ajena al mismo, ya que este patrimonio tiene una transcendencia que va más allá de la tangibilidad, pues esta impregnado de sensaciones, emociones, experiencias de tipo subjetivo que traspasa la lógica de los hechos cuantificables.

El Patrimonio Cultural inmaterial se define, según la Convención para la protección del patrimonio inmaterial de la Unesco ${ }^{2}$, como los usos, representaciones, expresiones, conocimientos y técnicas que las comunidades, los grupos y, en algunos casos, los individuos reconocen como parte integrante de su patrimonio cultural.

En el evento tradicional se produce una circunstancia y es que muchos de sus componentes son inmateriales o intangibles, es decir, se trata de patrimonio vivo, que se recrea constantemente, y que en muchos casos la transmisión oral es fundamental ya que el depositario de este patrimonio es la mente humana.

Por eso los eventos tradicionales, son parte del Patrimonio Cultural Inmaterial (PCI) que tienen los territorios. Estos, al ir evolucionando han ido configurando sus propias singularidades, en unión a la geografía, el clima, la historia y demás elementos que conforman el carácter de una zona o región y de las personas que la habitan.

Todos estos elementos forman parte de la identidad y cultura de una sociedad, siendo uno de sus activos más importantes que al tratarse en muchos casos de elementos no

\footnotetext{
${ }^{2}$ UNESCO. Convención para la salvaguarda del Patrimonio Cultural Inmaterial. París, 17 de Octubre de 2003
} 
tangibles, ha permanecido vivo gracias a la transmisión generación a generación configurando peculiaridades y sentido de arraigo que dota de carácter y diferenciación al territorio.

En este sentido, si lo ligamos al aumento del tiempo de ocio de las personas, así como su poder adquisitivo a un nuevo concepto del disfrute del tiempo libre más experiencial, comprenderemos que día a día el ser humano, ya cubiertas sus necesidades básicas, se preocupe de otras cuestiones que le permitan acercarse cada día más a una oferta cultural con la que enriquecer experiencias y contribuir al enriquecimiento personal, a través del ocio y disfrute.

\subsection{El Evento Tradicional, una nueva forma de atracción turística y de desarrollo territorial}

En los últimos tiempos se está produciendo una convergencia entre cultura y turismo, puesto que la cultura se comercializa y el turismo se culturiza De esta forma, en la sociedad actual, con la necesaria tendencia social hacia un mayor ocio y tiempo libre, la concepción del turismo deja de ser la tradicional, de largas estancias, para pasar a otro tipo de turismo, más perceptivo y experiencial, en donde la calidad y las vivencias requiere otro tipo de actividades.

Por otro lado, hoy en día es incuestionable la importancia de la imagen percibida de losterritorios que se pretende promocionar, puesto que va a ser en último caso el instrumento decisor de la elección del viajero consumidor. En este caso, cobra gran importancia la arquitectura de marca, construir para el territorio objeto del estudio, una marca fuerte, que determine no sólo como quiere ser visto hoy, sino como quiere que se le vea en el futuro, puesto que el presente tiene que gestionarse desde el futuro. Es en este momento cundo cobran importancia los valores como punto de referencia fundamental de captación y consolidación de nuestra oferta.

El evento tradicional se convierte en un valor que añadir a los atractivos del territorio y en muchos casos incluso llega a ser el valor fundamental: ¿Qué valores asociamos a ciudades como Pamplona, Rio de Janeiro o Buñol, por citar algunos ejemplos, obviamente San Fermín, Carnavales y La Tomatina.

En este sentido, a la hora de construir la identidad territorial para conseguir una imagen potente capaz de transmitir al público consumidor los mensajes vinculados con los conceptos patrimoniales intangibles del lugar se opta en muchos casos en plasmar experiencias, valores de la personalidad del propio lugar desarrollados a través de eventos. Estos, a la vez de ayudar a construir la marca identitaria del territorio, ayudan a que el público interiorice la imagen turística del mismo, convirtiéndolos en la bandera de su gente, de sus Instituciones dentro y fuera del propio lugar.

Por tanto, la organización de un evento, y en este caso de un evento tradicional, 
resulta paradigmática en el proceso de construcción de imágenes territoriales vividas in situ ${ }^{3}$. El evento tradicional pasa, de esta manera a favorecer el desarrollo del territorio donde se produce y contribuye en la mejora de la calidad de vida social e intelectual de los ciudadanos y de las ciudadanas del mismo.

Dentro del ADN de la marca ciudad, es fundamental su perfil cultural que supone la suma de valores y normas que son compartidas por personas y grupos de una organización y que controlan la manera de interactuar unos con otros y ellos con el entorno. En este sentido, los eventos tradicionales son el centro de la vida social y cultural de todas las ciudades y pueblos. Es la celebración máxima que unifica a todos los habitantes de ese lugar y que proporciona sensación de pertenencia. Pero además de simbolizar la unidad de esa ciudad, sus habitantes e instituciones, es en gran parte de las ocasiones, la carta de presentación de la ciudad ante sus visitantes.

Esto se debe a que en la fecha en las que se celebran las festividades tradicionales de una localidad, supone el momento en el que, generalmente, se dan cita el mayor número de visitantes. Es por ello por lo que su celebración y organización no puede es cuidarse, pues provocaría un fracaso en la organización del evento y, por consiguiente, la generación de una mala imagen por parte de la ciudad que lo acoge.

En otro orden de cosas, el turista atraído por el evento tradicional, no pretende ser un mero espectador sino integrarse y participar en la fiesta, por lo que sus simpatías hacia el evento y por extensión al territorio que lo acoge, le harán permeable a su buena disposición como correa de transmisión del mismo a través del boca oreja.

Pues con el evento tradicional se crea y difunde una imagen urbana positiva sobre la base de un sólido anclaje en su identidad y cultura, posicionando al territorio como destino turístico y sirviendo de escaparate para toda la oferta complementaria que dicho territorio pueda tener, gastronomía, museos, playas.... Así, el turista receptor ya no es sólo receptor-pasivo-comprador-consumidor, sino que pasa a integrarse en lo que Costa define como sistema intermedia ${ }^{4}$ de imagen de marca en el que dentro de la organización del territorio, el individuo también adquiere un papel activo pasando a ser emisor, intérprete y actor del mismo al poder interactuar con el espacio, los productos, y todos los demás elementos que conforman el evento tradicional.

\subsection{Utilización de las nuevas tecnologías de la comunicación en el citymarketing: Internet como forma de comunicar el territorio}

\footnotetext{
3 JIMÉNEZ MORALES, Mónika y SAN EUGENIO VELA, Jordi, (2009): “Identidad territorial y promoción turística: la organización de eventos como estrategia de creación, consolidación y difusión de la imagen de marca del territorio", Zer, Vol 14, n 26.

${ }^{4}$ COSTA, Joan (2004). La imagen de marca. Un fenómeno social. Paidos. Barcelona.
} 
Una vez apreciadas las posibilidades del evento tradicional como valor de atracción del turismo hacia el territorio que lo acoge, se ha de buscar los medios para comunicarlo al público potencial. En este aspecto, las nuevas tecnologías de la comunicación ayudarán a posicionar la oferta turística a un mercado más global.

En este sentido, el producto turístico es algo más que un producto de la información, puesto que los consumidores de destinos obtienen información sobre los mismos a través de diferentes canales: medios de comunicación, círculos cercanos (amistades, familiares, entorno laboral...), agencias de viajes., en definitiva, hablamos de comunicación personal, basada en la confianza pues hasta que no se consume el producto, no se materializan las expectativas, de esta manera la información se convierte en instrumento fundamental de la toma de decisión en la adquisición del producto turístico y por tanto dicha información debe ser de calidad.

De esta manera, Internet se convierte en el instrumento ideal para satisfacer esta necesidad de calidad de la información. Internet y la interactividad que lleva aparejada permiten a la gente encontrar información con rapidez y exactitud sobre cualquier destino o actividad de esparcimiento que le interesa y abre la posibilidad de poder obtener información instantánea y concebir la conveniencia del producto turístico que buscan y pagarlo en línea.

El sector turístico se convirtió en una de las primeras industrias en aplicar a partir de los años 60 el comercio electrónico de forma computerizada. Pero pese a la tradición de su uso, en las últimas décadas ha habido una revolución importante en la utilización de internet por el sector turístico, pues mientras en un principio la comunicación de la información se producía entre los diferentes agentes participantes en los negocios turísticos sin contar con el concurso de los consumidores, en la actualidad las compañías de reservas globales han comenzado a desarrollar sistemas basados en páginas web en donde la oferta de información es mucho más amplia y segura.

La difusión a través de la web, es hoy en día, un elemento imprescindible para salvar distancias y llegar a futuros públicos interesados convirtiéndose en una herramienta insustituible para acceder al público global. Internet proporciona al destino un medio eficaz para desarrollar una "infraestructura electrónica sostenible" que permite establecer un sitio comprensivo y multilingüe en la web del destino. Este sitio puede presentar a los turistas actuales y potenciales información actualizada, sobre el destino en todos sus aspectos - atracciones turísticas, transporte, comodidad, operadores de viaje, agencias de viajes, compras y recursos de ocio - así como su gente, cultura, historia, economía, clima.

Por tanto, la oferta turística se enfrenta a nuevos retos en la concepción de su comunicación. Sus puertas se han abierto ante sus públicos y los caminos para llegar a 
ellos han sido modificados.

Nuevas estrategias, nuevas herramientas, nuevos públicos y, ante todo, nueva actitud. Esta fuera de duda el potencial de las redes sociales y la posibilidad de apelar a las sensaciones, a las emociones, para captar y fidelizar al cliente. Los folletos de toda la vida han muerto, empresas y destinos luchan ahora para que el turista se enamore de ellos. En este escenario la página Web se convierte en una vitrina virtual que está expuesta a todo el mundo las 24 horas del día.

\subsection{Ventajas de la utilización de Internet para la promoción del turismo cultural}

Internet es una red global de redes de ordenadores intercomunicados y que funcionan con un protocolo estándar que permite que los datos sean transferidos entre éstos. Como sistema de intercambio de información, el aspecto más importante de Internet es su conectividad, definiendo ésta como la capacidad que permite que cada persona tenga acceso a la Red. El potencial de uso de Internet para las actividades de comercialización se deriva de su uso general como sistema de intercambio de información. La información se puede guardar, indexar, extraer, reestructurar y redistribuir automáticamente por un software lógico y sin intervención humana. Internet conecta empresas con empresas, empresas con los clientes, y a personas con personas.

En internet, existen principalmente dos categorías de servicios: de comunicación e informativos. Los primeros permiten el intercambio de información directa entre los usuarios de Internet y los segundos permiten la accesibilidad a los datos puestos a disposición de otros usuarios.

Las ventajas que ofrece la utilización de internet como instrumento promocional de la oferta turística son innegables. Por un lado la minimización del coste de la información, en concreto las páginas webs, proporcionan información que permite al consumidor/a encontrar por si mismos las respuestas a sus dudas con la consiguiente reducción de gastos telefónicos o de tiempo. Otra ventaja es su fácil accesibilidad, que como se ha señalado la convierten en vitrina permanente de exposición de ofertas a cualquier hora y en cualquier lugar del mundo. Además internet se muestra como un medio bidireccional, en donde el usuario deja de ser un sujeto pasivo para poder adaptar el producto a su propio interés. También permite la interactividad y flexibilidad de la oferta, pudiéndose obtener rápidas respuestas y adaptando las necesidades según la retroalimentación recibida. Todo ello comporta una mejora de los servicios ofrecidos que hacen ideal a Internet como medio de marketing turístico.

\subsection{Las Fiestas de la Magdalena de Castellón de la Plana}

Castellón de la Plana, ciudad mediterránea de la Comunidad Valenciana, es 
poseedora de un rico patrimonio cultural intangible compuesto por toda una serie de recursos entre los que cabe destacar su clima, paisajes, gastronomía, costumbres y tradiciones, donde destacan sus fiestas populares de gran colorido, belleza y originalidad. Estas, han sido declaradas recientemente por la Secretaria de Estado de Turismo como Fiestas de Interés Turístico Internacional a través de la resolución de 12 de marzo de 2010, suponiendo el reconocimiento del arraigo de este evento tradicional, por sus características etnológicas y sus valores culturales y de tradición popular que las hacen atractivas para el turismo, sobre todo cultural.

Castellón es una población abierta y luminosa, amplia y llana, con el mar en su frente y la montaña a sus espaldas. Es poseedora de un clima benigno y templado, lo que hace que sus tierras sean fértiles y ricas. En la actualidad es una ciudad moderna pero con un señorío y encanto provinciano, gracias a sus tradiciones, leyendas y hasta su propia mitología.

Por su seductora costa, el turismo de sol y playa ha sido el tradicional por autonomasia, apareciendo el resto de atractivos y valores como oferta complementaria al mismo. En este sentido, la apuesta por el turismo cultural tradicional, supone la diversificación de la oferta y la desestacionalización de la demanda, así como un aprovechamiento de infraestructuras que de otro modo quedarían inactivas

Las principales fiestas de la ciudad son las que conmemoran su fundación, las Fiestas de la Magdalena. Se trata de nueve días de fiesta que se estructuran desde el tercer sábado de Cuaresma hasta el cuarto domingo de este periodo. A partir del primer sábado de esta semana, comienzan un sinfín de actos y eventos (más de 250) que tienen su punto de arranque con un espectáculo pirotécnico diurno "la mascletá" inaugural. Desde ese momento, se puede oír por las calles de la villa, la música, petardos, volteos de campanas y demás.

Como actos más particulares de esta semana grande podemos destacar: La Cabalgata del Pregón, que es un desfile que enseña al espectador una verdadera muestra etnológica de las costumbres de los distintos pueblos de la provincia. Él pregón se estructura en tres partes: la primera trata de la historia de Castellón, donde el protagonismo lo tienen las tres culturas que convivieron en la época fundacional: cristianos, musulmanes y judíos, compiten en belleza de indumentaria, música, bailes y otras peculiaridades. La segunda parte se dedica a las costumbres, tradiciones y folclore de las distintas poblaciones de la provincia de Castellón, para finalizar con la parte dedicada al propio término municipal, con sus partidas y costumbres propias.

Pero el acto principal que da nombre a las fiestas es la Romería a la ermita de la Magdalena (también llamada romería de las cañas). Cuenta la leyenda, que hace más de siete siglos, un pueblo entero, dejó la montaña para establecerse en el llano. Allí alrededor de una humilde alquería musulmana, surgiría la villa, que luego sería Castellón. Durante el descenso, sobrevino la noche y la tempestad y para no perderse, aquellos primeros pobladores ataron pequeños faroles al extremo de los cayados 
y cañas con los que tanteaban el camino, para poder iluminarse.

Los niños llevaban en torno al cuello un pan cocido con forma de rollo e iban atados mediante cintas a los cayados iluminados que portaban sus padres. Esta leyenda, aporta la simbología principal de las fiestas castellonenses, los rollos, las cintas y pañuelos verdes, las cañas y los cayados que junto a los faroles fueron la base del monumento principal de Castellón, las Gaiatas.

De este modo, todo un pueblo de manera constante y prácticamente, ininterrumpida, sigue este ritual romero, repitiéndolo cada año al romper el primer albor del día. En ese momento toda una ciudad se moviliza, bajo el constante tañer de la campana Vicente, los cohetes y petardos, el tambor y la dulzaina, el murmullo de las cañas al rozar por el asfalto, los cánticos de los romeros tantos y tantos otros elementos de folcklore y tradición.

Cabe destacar, por otra parte, el protagonismo de las Gaiatas, monumentos de luz exclusivos de Castellón, los cuales desfilan en la noche del tercer domingo de Cuaresma y permanecen en distintas plazas de la ciudad a lo largo de toda la semana de fiestas, coincidiendo con los diferentes sectores de la ciudad. Cada sector tiene su gaiata y su comisión. Estos, portando la indumentaria tradicional (los trajes de castellonera/o y de labrador/a inspirados en el siglo XVIII) adornaran la semana de fiestas, con su participación en actos y desfiles por toda la villa.

Durante toda la semana se suceden los conciertos, los espectáculos pirotécnicos y taurinos, las actuaciones de grupos de teatro de calle, las verbenas, los desfiles y las cenas populares con su consabido baile en la plaza. Cabe destacar el coso multicolor, donde las comisiones de gaiata entablan una lucha campal de confeti que tiran desde las carrozas a la gente que participa en este recorrido, también las visitas a los mesones del vino o de la tapa y la cerveza, den donde multitud de casetas dan muestra de la gastronomía y caldos de la tierra para goce de propios y forasteros.

Los castillos de fuego y las monumentales mascletadas, se suceden a lo largo de toda la semana dando muestra del carácter vital de los castellonenses. Finalmente, la semana festiva se cierra con la celebración de la ofrenda a la Mare de Déu del Lledó, patrona de la ciudad y el Magdalena Vitol, broche de oro de estas fiestas, que se caracterizan por ser fiestas populares y que se celebran en la calle, donde todo el mundo puede participar.

Castellón, ciudad abierta, acoge de manera especial al visitante la semana de las Fiestas de la Magdalena. La gastronomía, la música, la danza, el folclore, la cultura, la historia, la pirotecnia, los espectáculos taurinos, el fervor...todo se conjuga para 
formar un crisol que enamora al espectador que por primera vez llega a esta tierra y que seguro volverá otra vez.

\subsection{FestaPèdia, un proyecto en la red para informar sobre la fiesta tradicional}

FestaPèdia 5 , es un proyecto que surge de la idea de una asociación cultural castellonense "la gaiata 8, Portal de l'Om". Sus componentes vieron la conveniencia de crear una enciclopedia sobre la Magdalena de manera virtual, al comprobar que mucha información sobre el mundo del evento tradicional de Castellón y en concreto, sobre sus principales fiestas, la Magdalena, se estaban perdiendo.

Un poco a imagen y semejanza de Wikipedia, el impulso de esta asociación junto con la importante colaboración de personas principales del mundo de la cultura castellonense, hizo que viese la luz este proyecto en marzo de 2011. Así nace FestaPèdia un proyecto de documentación, en valenciano, sobre las fiestas de la Magdalena, y especialmente sobre las figuras que han sido protagonistas, sobre todo desde 1945, fecha de la renovación de las Fiesta, hasta la actualidad. Actualmente cuenta con 2.650 entradas o definiciones.

La realidad es que poca información sobre las fiestas de la Magdalena de Castellón se podía encontrar a nivel global. En Wikipedia sólo existía un breve artículo sobre las mismas, y en cualquier caso la aparición del programa de festejos que año tras año se va realizando, no cuenta con datos o información sobre los aspectos culturales de este evento, sino que se trata de un cronograma de actos, con su horario y localización. Por eso, FestaPèdia es un proyecto pionero para ser referente dentro del mundo del evento tradicional.

En la actualidad se recoge los elementos documentales fundamentales de la historia tradicional castellonense, que pretende, desde la perspectiva local, tener una aplicación universal. En este proyecto global, que ahora se encuentra en Internet, aparecen todos los componentes que vertebran el mundo de la fiesta de la ciudad y que se estructuran en seis campos: a) integrantes de la fiesta/festeros/as; b) colectivos; c) actos; d) lugares; e) conceptos y f) publicaciones.

a) Integrantes de la fiesta/festeros/as: Se recoge en este apartado la información de las personas vinculadas de manera personal a algún ente $u$ organización dentro del Mundo de la fiesta. (Presidentes de la Junta, presidentes de comisiones de sector, artistas gaiateros, diversos miembros de la Junta de Festes, así como todas las reinas, damas de la ciudad, incluidas las Violants, «dones de companya» y madrinas, tanto mayores como infantiles, que se ha podido documentar). De esta manera este apartado se divide en: 1) Listado general, 2) Junta de Fiesta, 3) Gaiatas, 4) Entes vinculados y 5) Entes no vinculados. A su vez, también se estructuran por orden alfabético y cargos

\footnotetext{
${ }^{5}$ www.festapedia.org
} 
ostentados en los diferentes colectivos. Para poder completar los datos sobre estas personas, la comisión que realiza FestaPèdia ha realizado una labor ingente de búsqueda, que no en todos los casos ve la luz, ya que respetando lo que señala la legislación sobre la protección de datos de carácter personal, dicha información debe ser consentida por las personas implicadas de manera fehaciente, a través de la firma autógrafa del documento de aceptación que FestaPèdia pone a disposición de cualquier interesado/a.

b) Colectivos: Aquí se recogen los cuatro grupos de colectivos de la fiesta castellonense: 1) Gaiatas, 2) Collas, 3) Entes vinculados y 4) Otros colectivos. Dentro de cada colectivo, se recoge el listado de los grupos integrantes, y los links con la información de cada uno.

c) Actos: En este punto se enuncian los actos/eventos que componen las fiestas populares de Castellón, principalmente los de la Magdalena, y se aportan artículos y links sobre su historia, desarrollo, ubicación etc.

d) Lugares: En este apartado, se señalan los lugares más emblemáticos para el desarrollo del evento tradicional en la ciudad de la Plana, asimismo, se explica el significado de los mismos y su emplazamiento y manera de llegar al mismo.

e) Conceptos: Es fundamental entender la terminología que se emplea alrededor de este tipo de evento tradicional. En Castellón junto al castellano convive la lengua valenciana que es la principalmente utilizada en el mundo del folcklore y tradición. Por este motivo, palabras que se han castellanizado por el uso, pueden parecer extrañas para el forastero cuando se descontextualizan. Otras palabras, por ser propias a este mundo, son desconocidas para el extraño, por lo que es necesario explicarlas.

f) $\underline{\text { Publicaciones, }}$ se recogen todos aquellas publicaciones en donde se puede ampliar sobre el conocimiento de la fiesta tradicional.

Este es el proyecto FestaPèdia, que permite conocer la realidad sobre el evento tradicional en Castellón y que pretende ser referente para otras fiestas, con el propósito de conseguir que la Cultura tradicional folcklórica de los pueblos no se pierda, ya que es un importante activo intangible que aporta al territorio valor y singularidad.

\section{CONCLUSIONES}

En la actualidad, ha quedado de manifiesto, la enorme importancia que tiene el patrimonio cultural tradicional, como patrimonio intangible, ya que además de suponer un elemento diferenciador de las localidades se convierte, de esta manera, en instrumento fundamental para la potenciación y singularización de los territorios, y factor de desarrollo económico al desestacionalizar la oferta, potenciar los elementos propios y desarrollar sectores económicos que de otra manera podrían desaparecer.

Los eventos tradicionales de los territorios, son parte de este patrimonio cultural inmaterial. Como bien intangible, debe velarse por su protección, ya que puede ser fuente de atracción de un nuevo turismo, que busca en las experiencias una respuesta 
y un atractivo para contratar el producto. En este sentido, la potenciación correcta de la gestión del patrimonio tradicional, supone una mejora importante en la imagen percibida del territorio y sus productos complementarios, por eso deben buscarse fórmulas para llegar a gran parte del público global.

Internet, permite ese acceso global, apoyado en la reducción de costes y en la bidireccionalidad y flexibilidad de este medio, así como su fácil accesibilidad. Hoy en día, en el que los cambios sobre las maneras de disfrutar del ocio comportan destinos culturales y experienciales, los eventos tradicionales, pueden ayudar a posicionar los territorios. Con proyectos como Festapèdia, se ayuda a conocer el patrimonio cultural de los pueblos, así como sirven de reclamo para tener una experiencia más entendible y auténtica.

\section{REFERENCIAS}

Bernad Monferrer, E. (2009). Fiestas Populares y Gestión Cultural: Las Fiestas de la Magdalena como instrumento de proyección territorial. En La Gestión de Intangibles: Impacto en el desarrollo territorial. Castellón.

Costa, J. (2004). La imagen de marca. Un fenómeno social. Barcelona: Paidos.

Jiménez Morales, M. \& San Eugenio Vela, J., (2009). Identidad territorial y promoción turística: la organización de eventos como estrategia de creación, consolidación y difusión de la imagen de marca del territorio. Zer, 14(26).

UNESCO. (2003). Convención para la salvaguarda del Patrimonio Cultural Inmaterial. Paris.

\section{María Estela Bernad Monferrer}

Licenciada Derecho Universidad Valencia. Doctora Comunicación Universitat Jaume I. Profesora desde 1.991. Actualmente miembro Departamento Ciencias Comunicación. Profesora de Comunicación Audiovisual, Publicidad y Periodismo y Master Nuevas Tendencias y Procesos de Innovación en Comunicación. Directora del Curso especialista Universitario UJI: “Gestión de eventos y acciones para la reputación”. Ha sido Vicesecretaria General de la Universitat Jaume I, y secretaria de la Facultad de Ciencias Humanas y Sociales.Es miembro del Grupe de Recherche Images Teretes Colela Jeunesse (GRITEJ) del Institute Catholique de Toulouse, Francia.

\section{Magdalena Mut Camacho}


Doctora en Comunicación empresarial e institucional por la Universitat Jaume I de Castellón y licenciada en Ciencias de la información por la Universidad Autónoma de Barcelona. Profesora del Departamento de Ciencias de la Comunicación en la titulación de Publicidad y RRPP, en la de Comunicación Audiovisual y en el Máster Oficial en Nuevas Tendencias y Procesos de Innovación en Comunicación de la Universitat Jaume I de Castelló. Profesora de máster en la Universidad Autónoma de Barcelona y en la Universidad de Valencia. Es co-directora junto a Joan Costa del Máster Internacional de Dirección y Gestión de la Comunicación para Latinoamérica 